\title{
Communication
}

\section{Genetic Variation and Phylogeny of Wabisuke Camellias by Amplified Fragment Length Polymorphism (AFLP) Analysis}

\author{
Jung-Hee Kim ${ }^{1}$, Itsumi Koike ${ }^{2}$, Toshiki Nakashima ${ }^{3}$, Michikazu Hiramatsu ${ }^{4}$, Ikuo Miyajima ${ }^{5}$, Yuki Mizunoe ${ }^{2}$, \\ Hiroshi Okubo ${ }^{2}$ and Yukio Ozaki ${ }^{2, *}$ (1) \\ 1 Graduate School of Sciences and Technology for Innovation, Yamaguchi University, Yoshida, \\ Yamaguchi 753-8515, Japan; kim@yamaguchi-u.ac.jp \\ 2 Faculty of Agriculture, Kyushu University, Fukuoka 819-0395, Japan; camellia1235@gmail.com (I.K.); \\ mizunoe.yuki.923@m.kyushu-u.ac.jp (Y.M.); yhokubo@yahoo.co.jp (H.O.) \\ 3 Saga Prefecture Agriculture Research Center, Nanri, Kawasoe, Saga 840-2205, Japan; \\ nakashima-toshiki@pref.saga.lg.jp \\ 4 Institute of Decision Science for a Sustainable Society, Kyushu University, Fukuoka 819-0395, Japan; \\ mich.katz1965@gmail.com \\ 5 Institute of Tropical Agriculture, Kyushu University, Fukuoka 819-0395, Japan; imiyajima@agr.kyushu-u.ac.jp \\ * Correspondence: y.ozaki.255@m.kyushu-u.ac.jp; Tel.: +81-92-802-4564
}

Citation: Kim, J.-H.; Koike, I.; Nakashima, T.; Hiramatsu, M.; Miyajima, I.; Mizunoe, Y.; Okubo, H.; Ozaki, Y. Genetic Variation and Phylogeny of Wabisuke Camellias by Amplified Fragment Length Polymorphism (AFLP) Analysis. Agronomy 2021, 11, 1974. https:// doi.org/10.3390/agronomy11101974

Academic Editors: Agnieszka

Marasek-Ciolakowska and

Dariusz Sochacki

Received: 24 August 2021

Accepted: 28 September 2021

Published: 30 September 2021

Publisher's Note: MDPI stays neutral with regard to jurisdictional claims in published maps and institutional affiliations.

Copyright: (c) 2021 by the authors. Licensee MDPI, Basel, Switzerland. This article is an open access article distributed under the terms and conditions of the Creative Commons Attribution (CC BY) license (https:// creativecommons.org/licenses/by/ $4.0 /)$.

\begin{abstract}
Amplified fragment length polymorphism (AFLP) analysis was conducted on the wabisuke camellia and its relative camellia species. Genetic polymorphism was identified among the 'Uraku' camellia, its offspring 'Tosa-uraku' and Camellia japonica, whereas the two accessions of the old 'Uraku' showed monomorphism in all the fragments. The results suggested that the two old 'Uraku' trees are asexually-propagated clonal strains. The genetic distance between wabisuke cultivars and Chinese camellias and between wabisuke camellias and $C$. sinensis was much further than that between wabisuke cultivars and Camellia japonica. It has also been suggested that wabisuke camellias can be classified into two subgroups, I-1 and I-2, and that Subgroup I-2 originated from C. japonica, while Subgroup I-1, including 'Uraku' (synonym: 'Tarokaja'), was developed by the repeated hybridization of $C$. japonica to interspecific hybrids with the Chinese camellias, e.g., C. pitardii var. pitardii, or by the involvement of related species not investigated in this study.
\end{abstract}

Keywords: AFLP; genetic variation; phylogeny; wabisuke camellia

\section{Introduction}

Wabisuke camellias are a group of ornamental horticultural cultivars developed in Japan that have been praised for their remarkable characteristics, such as early flowering, small single flowers and sterile pistils [1]. The plants have often been used as a decorative flower in the Japanese tea ceremony. 'Tarokaja' (C. wabisuke Kitam., formerly C. uraku Kitam.) is one of the oldest wabisuke cultivars and is considered to be the same as the cultivar known as 'Uraku' (C. wabisuke) in western Japan [2]. Miyajima et al. [3] reported that old camellia 'Uraku' trees, existing in the gardens of historic temples and houses in Kyoto, Nara and Miyazaki Prefectures, are clonal strains which proliferated more than 400 years ago by vegetative propagation.

It was reported that wabisuke camellias could be classified into two groups [1]. One group is 'Tarokaja' and its offspring cultivars, which have elliptical acuminate leaves. Most of this group have pubescent ovaries, and the cultivars show seed sterility, with the exception of the low seed fertility of 'Tarokaja' [1,4]. The other group is thought to be derived from C. japonica L., and the cultivars generally have red flowers with glabrous ovaries and degenerated anthers. However, there have been some confusion about the categorization of wabisuke cultivars. One theory is that only those cultivars with small flowers and degenerated anthers that are the progeny of 'Tarokaja' are called wabisuke cultivars (narrow sense). Alternatively, those cultivars with small flowers and degenerated 
anthers established from C. japonica, not 'Tarokaja', are sometimes called wabisuke cultivars (broad sense). There are also some cultivars called "wabisuke" that have normal anthers with fertile pollen.

'Tarokaja' blooms pale purplish pink fragrant flowers from December to April, and these characteristics, as well as the pubescent ovaries, are not observed in C. japonica. The origin of 'Tarokaja' has long been debated. It has been reported that $C$. pitardii Cohen-Stuart var. pitardii $(2 \mathrm{n}=2 \mathrm{x}=30)[1,4], C$. saluenensis Stapf ex Bean $(2 \mathrm{n}=2 \mathrm{x}=30)[5,6]$, C. reticulata Lindl. $(2 n=6 x=90)$ [6] and C. sinensis (L.) O. Kuntze $(2 n=2 x=30)$ [7] were involved in the establishment of 'Tarokaja'. Tanikawa et al. [8] reported that the maternal origin of 'Tarokaja' is the Chinese native species C. pitardii var. pitardii, from the results of a PCRRFLP and sequence analysis of the atpI-atpH region in chloroplast DNA. Furthermore, Tanaka et al. [4] stated that 'Tarokaja' is considered to be an $\mathrm{F}_{1}$ hybrid of $C$. pitardii and C. japonica from a morphological and historical survey. On the other hand, the unique pigment urakunoside, a new tetraglycosyl kaempferol, isolated from the pale purplish pink petals of 'Tarokaja' was not found in the petals of C. pitardii var. pitardii [9].

In the camellia species, there are many excellent and sophisticated classical ornamental cultivars, whose origins are not clear, in camellia species. It is important to clarify the origins of the classical cultivars for further progress in developing new horticultural cultivars. As it is quite difficult to elucidate the origins of the classical cultivars from old records, molecular biological techniques have been applied to overcome the problem. Amplified fragment length polymorphism (AFLP) analysis has the advantage of both restriction fragment length polymorphism (RFLP) and random amplified polymorphic DNA (RAPD), and can easily detect genetic polymorphisms in the whole genome among accessions, as shown in coconut palm [10], persimmon [11], Hordeum [12,13], Lens [14] and Spiraea [15]. In this study, we conducted AFLP analysis on wabisuke camellias in the two groups and relative Camellia species that have been implicated in the establishment of wabisuke camellias, and investigated the genetic variation and phylogeny of wabisuke camellias.

As described earlier, 'Uraku' is considered to be a synonym of 'Tarokaja'. As the old tree accession used in this study is called 'Uraku', we use the same name in this paper.

\section{Materials and Methods}

\subsection{Plant Materials}

Two old 'Uraku' camellia tree accessions, 23 wabisuke camellia cultivars, five C. japonica natural accessions, three Chinese relative species and three Japanese tea (C. sinensis) cultivars were used as plant materials (Table 1). One C. sasanqua accession from Saga Prefecture was also used in the investigation.

Table 1. Wabisuke camellias and other relative species used for the research.

\begin{tabular}{ll}
\hline Species/Cultivars & Information on Accession Origin/Collection \\
\hline Wabisuke camellias & \\
Ohae-uraku & 'Uraku' from Saito City, Miyazaki Prefecture, Japan \\
Momigio-uraku & 'Uraku' from Saito City, Miyazaki Prefecture, Japan \\
'Beni-wabisuke' & Synonym. Kuro-wabisuke, Kyushu University (KU) collection \\
'Eiraku' & KU collection \\
'Eishiji-wabisuke' & KU collection \\
'Fukurin-ikkyu' & KU collection \\
'Goman-Goku' & KU collection \\
'Hamochi-wabisuke' & KU collection \\
'Hina-wabisuke' & KU collection \\
'Ichiko-wabisuke' & KU collection \\
'Ikkyu' & KU collection \\
'Kanzaki-aka-wabisuke' & KU collection \\
'Kocho-wabisuke' & KU collection \\
'Kon-wabisuke' & KU collection \\
'Kurume-ikkyu' & KU collection \\
\hline
\end{tabular}


Table 1. Cont.

\begin{tabular}{ll}
\hline Species/Cultivars & Information on Accession Origin/Collection \\
\hline 'Misho' & KU collection \\
'Miyo-no-sakae' & KU collection \\
'Otohime' & KU collection \\
'Sado-wabisuke' & KU collection \\
'Sayo-wabisuke' & KU collection \\
'Seiobo' & KU collection \\
'Shibenashi-wabisuke' & KU collection \\
'Showa-wabisuke' & KU collection \\
'Sukiya' & KU collection \\
'Tosa-uraku' & KU collection \\
C. japonica & Natural accession collected from Aomori Prefecture, Japan \\
Aomori & Natural accession collected from Iwate Prefecture, Japan \\
Iwate & Natural accession collected from Goto Islands, Nagasaki \\
Goto & Prefecture, Japan \\
& Natural accession collected from Hirado, Nagasaki Prefecture, \\
Hirado & Japan \\
Kagoshima & Natural accession collected from Kagoshima Prefecture, Japan \\
Chinese relative species & \\
C. pitardii var. pitardii & Collected from Sichuan, China \\
C. reticulata & Collected from Yunnan, China \\
C. saluenensis & Collected from Yunnan, China \\
Japanese tea cultivars & \\
'Asatsuyu' & Saga Tea Research Laboratory (STRL) collection \\
'Kanayamidori' & STRL collection \\
'Yabukita' & STRL collection \\
Outgroup & Natural accession collected from Saga Prefecture, Japan \\
C. sasanqua &
\end{tabular}

\subsection{AFLP Analysis}

Total DNA was extracted from frozen foliar buds following the modified cetyl trimethyl ammonium bromide (CTAB) methods by Kobayashi et al. [16] and adjusted to $100 \mathrm{ng} / \mu \mathrm{L}$. AFLP analysis was conducted using the following procedure. Approximately $250 \mathrm{ng}$ of total DNA was digested with $2.5 \mathrm{U}$ of EcoRI (Toyobo Co., Ltd., Osaka, Japan) and $0.5 \mathrm{U}$ of MseI (New England Biolabs. Inc., Beverly, MA, USA), and ligated to 0.5 U of EcoRI and MseI adaptor pairs (Applied Biosystems Inc., Foster, CA, USA) with 25 U of T4 DNA ligase (Nippon Gene Co., Ltd., Tokyo, Japan) in a total volume of $5 \mu \mathrm{L}$ containing $10 \times \mathrm{T} 4$ ligase buffer with ATP (Nippon Gene Co. Ltd., Tokyo, Japan) $0.025 \mathrm{ng}$ of bovine serum albumin (BSA, Takara Bio Inc., Kusatsu, Japan) and $50 \mathrm{mM}$ of $\mathrm{NaCl}$ (Nacalai Tesque Inc., Kyoto, Japan) for $12 \mathrm{~h}$ at $22{ }^{\circ} \mathrm{C}$. Next, the reaction was stopped for $20 \mathrm{~min}$ at $65^{\circ} \mathrm{C}$ and stored at $4{ }^{\circ} \mathrm{C}$ until the amplification procedure. The digested-ligated DNA fragments were diluted 1:10 with $0.1 \mathrm{M}$ of Tris-EDTA (TE) buffer and used as templates for the first amplification reaction.

The preselective PCR was performed in a $10 \mu \mathrm{L}$ solution, containing Core Mix and Preselective Primer pair (EcoRI+A. MseI+C) provided as an AFLP Ligation and Preselective Amplification Module (Applied Biosystems, Inc., Foster, CA, USA) and diluted digestedligated DNA product following the Applied Biosystems protocol. The PCR was performed using a GeneAmp PCR System 9700 (Applied Biosystems Inc., Foster, CA, USA) under a temperature program of 1 cycle for $30 \mathrm{~s}$ at $94{ }^{\circ} \mathrm{C}+20$ cycles for $30 \mathrm{~s}$ at $94{ }^{\circ} \mathrm{C}$, for $1 \mathrm{~min}$ at $56{ }^{\circ} \mathrm{C}$, and for $2 \mathrm{~min}$ at $72{ }^{\circ} \mathrm{C}$. The pre-amplification products were supplied to the electrophoresis in a $1.5 \%$ agarose gel and irradiated with UV light for the confirmation of the amplified products $(<500 \mathrm{bp})$. Five-microliter pre-amplification products were diluted with $95 \mu \mathrm{L}$ of $1 / 10 \mathrm{TBE}$ and provided as the template in the selective PCR.

The selective PCR was performed in a $5 \mu \mathrm{L}$ solution containing a diluted primary amplification product, 0.125 U Ex Taq polymerase (Takara Bio, Kusatsu, Japan), and an 
attached 10x Ex Taq buffer, $0.16 \mathrm{mM}$ dNTPs mix, with each selective primer (EcoRI + Axx, MseI + Cxx) in an AFLP Selective Amplification Start-Up Module (Applied Biosystems Inc., Foster, CA, USA) following the Applied Biosystems protocol. The primer pairs used in this study were E-ACT/M-CAC, E-AAC/M-CAA, E-AAC/M-CAC, E-AAG/M-CTC, E-AAG/M-CAC, E-ACA/M-CTC and E-AGG/M-CTC (Applied Biosystems Inc., Foster, CA, USA). The selective PCR was carried out using a Gene Amp PCR System 9700 (Applied Biosystems Inc., Foster, CA, USA) under a temperature program of 1 cycle for 2 min at $94{ }^{\circ} \mathrm{C}, 10$ cycles for $20 \mathrm{~s}$ at $94{ }^{\circ} \mathrm{C}, 30 \mathrm{~s}$ at $65^{\circ} \mathrm{C}$ (with the annealing temperature reduced by $1.0^{\circ} \mathrm{C}$ at each cycle), $2 \mathrm{~min}$ at $72{ }^{\circ} \mathrm{C}, 23$ cycles for $20 \mathrm{~s}$ at $94{ }^{\circ} \mathrm{C}, 20 \mathrm{~s}$ at $56{ }^{\circ} \mathrm{C}$ and $2 \mathrm{~min}$ at $72{ }^{\circ} \mathrm{C}$, then 1 cycle for $30 \mathrm{~min}$ at $60^{\circ} \mathrm{C}$.

Deionized formamide (FUJI FILM Wako Pure Chemical Corp., Osaka, Japan) and Gene Scan 500 ROX (Applied Biosystems Inc., Foster, CA, USA) were mixed with the amplified solution, and electrophoreses of the mixtures were performed with an automated sequencer ABI PRISM 310 Genetic Analyzer (Applied Biosystems Inc., Foster, CA, USA).

Digital profiles were visualized with the aid of ABI Genescan software (Applied Biosystems Inc., Foster, CA, USA). Distinguishable AFLP markers were transformed into a binary matrix, with " 1 " for the presence and " 0 " for the absence of a fragment. The genetic distance between the accessions was calculated based on pairwise comparisons according to Nei [17] using RESTDIST, and the genetic distance matrix was used to draw a neighbor-joining (NJ) tree [18] utilizing NEIGHBOR and DRAWTREE in a package of programs for inferring phylogenies (PHYLIP version 3.6) [19].

\section{Results}

\subsection{Genetic Identity of Two Old 'Uraku' Accessions}

Only the AFLP markers that could clearly distinguish the presence or absence of peaks were only evaluated. Figure 1 shows part of the AFLP patterns of two accessions of 'Uraku', 'Tosa-uraku' and wild C. japonica from Kagoshima Prefecture with the primer EAGG/M-CTC. DNA polymorphism among 'Uraku', 'Tosa-uraku' and wild C. japonica was clearly detected by AFLP analysis, as indicated by the arrows in the figure. AFLP analysis with seven primer pairs revealed 197 markers in these four accessions, $40 \%$ of which were polymorphic. Two accessions of 'Uraku' obtained 162 markers, and no polymorphism was found between the accessions. Polymorphism among all the accessions tested in this study was recognized with the exception of two 'Uraku' accessions.

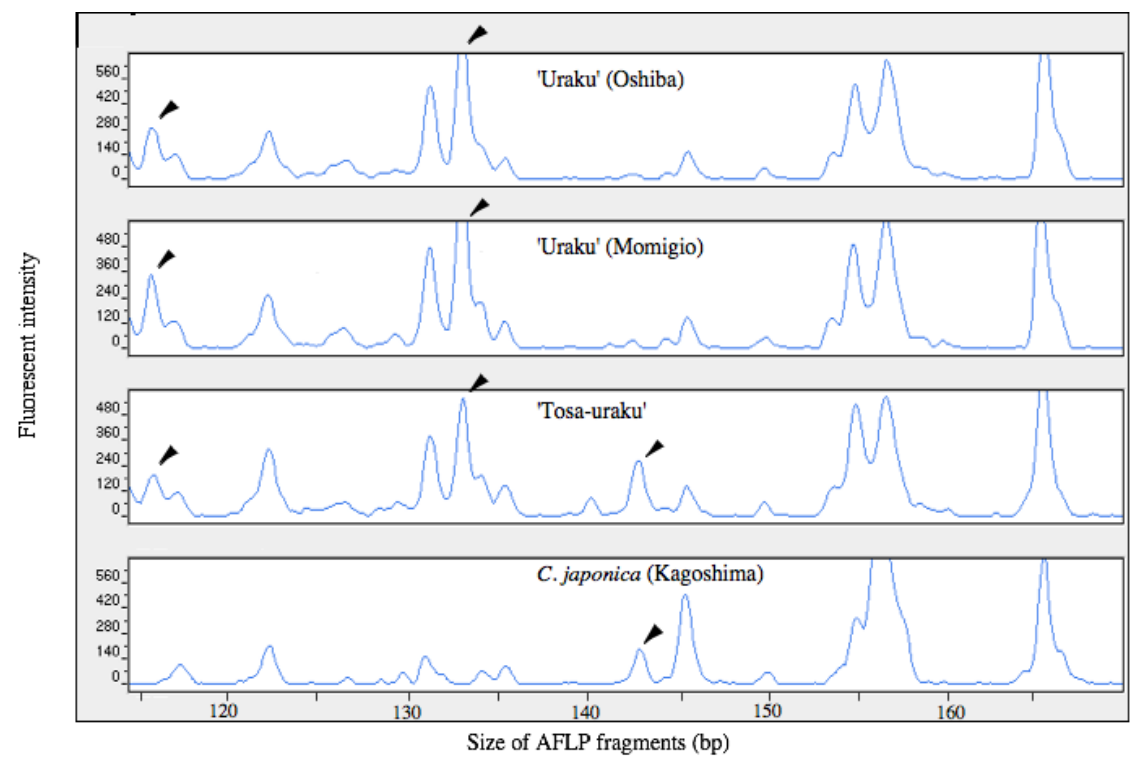

Figure 1. AFLP fragments of camellia accessions obtained with E-AGG/M-CTC primers. Arrows indicate the polymorphic fragments among the accessions. 


\subsection{Genetic Variation in Wabisuke Camellias}

The number of AFLP fragments using seven combinations of primers in all cultivars/species are shown in Table 2. A total of 333 fragments were obtained by seven primer combinations, and $279(84 \%)$ of them were detected as polymorphic markers. The highest percentage of polymorphic markers was generated with the combination E-AAC/M-CAA (92\%) and the lowest with E-AAG/M-CAA (66\%). All the accessions of the cultivars/species could be clearly distinguished in all primer combinations.

Table 2. Number of AFLP fragments using seven combinations of primer pairs in wabisuke and other camellias.

\begin{tabular}{cccc}
\hline \multirow{2}{*}{ Primer Pairs } & \multicolumn{3}{c}{ No. of Fragments } \\
\cline { 2 - 4 } & Total & Monomorphic (\%) & Polymorphic (\%) \\
\hline E-ACT/M-CAC & 63 & $9(14)$ & $54(86)$ \\
E-AAC/M-CAA & 51 & $4(8)$ & $47(92)$ \\
E-AAC/M-CAC & 41 & $8(20)$ & $33(80)$ \\
E-AAG/M-CAA & 41 & $14(34)$ & $27(66)$ \\
E-AAG/M-CAC & 57 & $7(12)$ & $50(88)$ \\
E-ACA/M-CTC & 32 & $7(22)$ & $25(78)$ \\
E-AGG/M-CTC & 48 & $5(10)$ & $43(90)$ \\
\hline Total & 333 & $54(16)$ & $279(84)$ \\
\hline
\end{tabular}

The genetic distance between the accessions was calculated from the presence or absence of the fragments, and the maximum (1.2735) and minimum (0.1083) genetic distances were observed between $C$. pitardii var. pitardii and C. sinensis 'Yabukita', and between 'Uraku' and its progeny 'Tosa-uraku', respectively. Table 3 summarizes the mean values and ranges of the genetic distance within wabisuke camellias, C. japonica, Chinese camellias and C. sinensis, and between wabisuke camellias and C. japonica, between wabisuke camellias and Chinese camellias, and between wabisuke camellias and C. sinensis. The mean values of the genetic distances between wabisuke camellias and Chinese camellias and between wabisuke camellias and C. sinensis were 0.8395 and 1.0576, respectively, while the mean value of the genetic distance between wabisuke camellias and C. japonica was 0.3902 , which was similar to the mean values within wabisuke camellias (0.3380) and within C. japonica (0.3682).

Table 3. Genetic distance within and between groups in camellia accessions.

\begin{tabular}{lcc}
\hline \multirow{2}{*}{ Within and between Groups } & \multicolumn{2}{c}{ Genetic Distance } \\
\cline { 2 - 3 } & Mean & Range \\
\hline Within groups & & \\
$\quad$ Wabisuke camellias & 0.3380 & $0.1083-0.5495$ \\
$\quad$ C. japonica & 0.3682 & $0.3138-0.4391$ \\
$\quad$ Chinese camellias & 0.5337 & $0.3313-0.7113$ \\
$\quad$ C. sinensis & 0.1660 & $0.1231-0.2274$ \\
Between groups & & \\
$\quad$ Wabisuke-C. japonica & 0.3902 & $0.2788-0.5150$ \\
$\quad$ Wabisuke-Chinese & 0.8395 & $0.6683-1.1582$ \\
camellias & 1.0576 & $0.8705-1.2339$ \\
$\quad$ Wabisuke-C. sinensis & &
\end{tabular}

The phylogenetic tree generated by the neighbor-joining method using genetic distance as an indicator is shown in Figure 2. The 36 accessions, in which two 'Uraku' accessions were treated as one cultivar due to the same AFLP patterns, were divided into four groups. The first group (Group I) included 24 wabisuke cultivars and 5 accessions of $C$. japonica, and the second group (Group II) comprised Chinese camellias: 
C. pitardii var. pitardii, C. saluenensis and C. reticulata. The third group (Group III) contained three $C$. sinensis cultivars and the fourth (Group IV) encompassed C. sasanqua. The first group could be further classified into two subgroups. Subgroup I-1 included 'Uraku', its progeny 'Tosa-uraku' and 13 other wabisuke cultivars, and Subgroup I-2 was composed of 9 wabisuke cultivars and 5 C. japonica accessions.

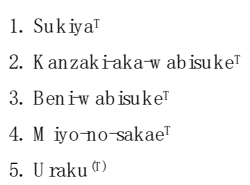

Group II

30 C. pitardii var. pitardii

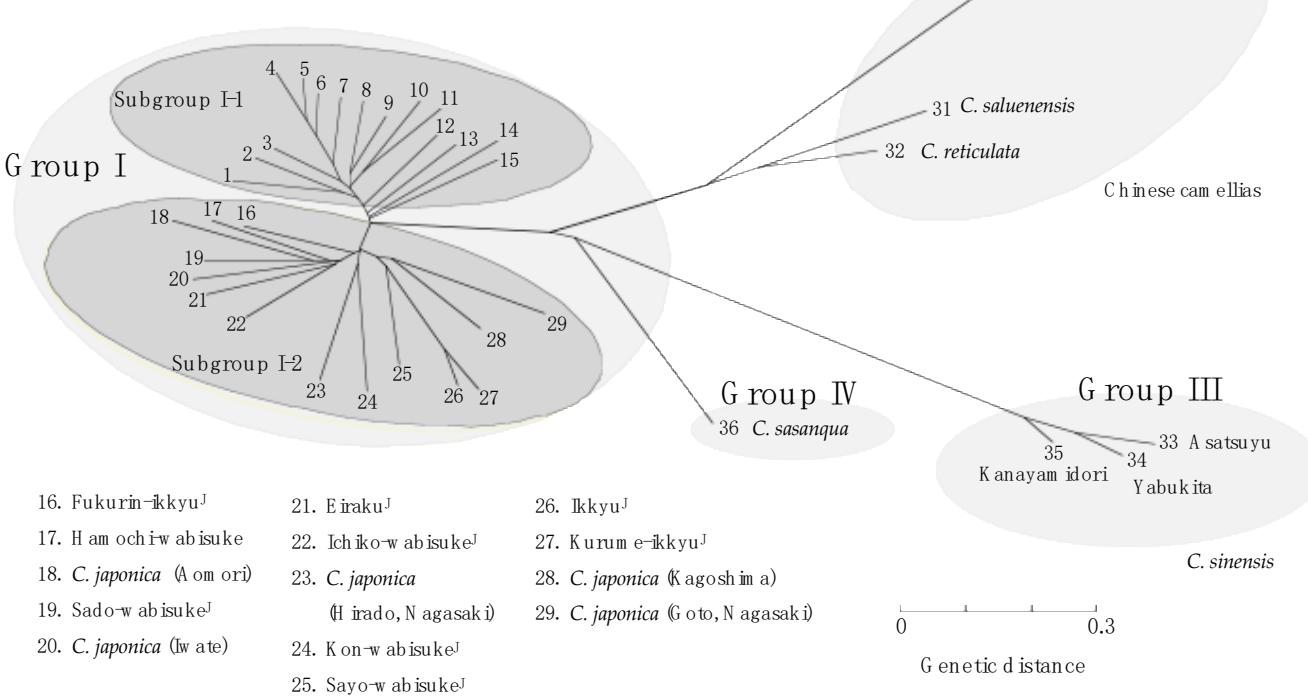

Figure 2. Unrooted phylogenetic tree of wabisuke and other camellias from the neighbor-joining method based on AFLP analysis using seven primer combinations. Cultivars with superscripts T and J indicate wabisuke cultivars established from 'Tarokaja' (synonym: 'Uraku') and from C. japonica as sports, respectively.

\section{Discussion}

Camellias are known to be allogamous plants in general. Furthermore, the 'Uraku' used in the experiment was a male sterile cultivar, so that self-pollination was impossible. In this study, AFLP analysis detected the genetic polymorphism between 'Uraku' and its progeny 'Tosa-uraku' [20], showing the usefulness of the AFLP markers in genetic fingerprinting. Miyajima et al. [3] reported that there was no difference in the band patterns between the two accessions of old 'Uraku' by RAPD analysis, suggesting that these old trees are clones that have vegetatively propagated. The current AFLP results coincide with the report of Miyajima et al. [3]. Therefore, the two accessions of old 'Uraku' were found to be vegetatively propagated identical 'Uraku'.

It has been suggested that wabisuke camellias can be classified into two groups, namely small flower cultivars with degenerated anthers, which are called "wabi-shin", "from "Tarokaja'" and "from C. japonica". The current study confirmed the suggested distinction that wabisuke camellias could be divided into two (sub)groups. Subgroup I-1 was composed of 15 wabisuke cultivars, and Subgroup I-2 comprised 9 wabisuke cultivars, as well as 5 C. japonica accessions. Subgroup I-1 included 'Beni-wabisuke', 'Eishojiwabisuke', 'Gomangoku', 'Hina-wabisuke', 'Kanzaki-aka-wabisuke', 'Kocho-wabisuke', 'Miyo-no-sakae', 'Otohime', 'Shibenashi-wabisuke', 'Showa-wabisuke', 'Sukiya' and 'Tosauraku', which are reported to have originated from 'Tarokaja (Uraku)' [1,20,21]. It was also reported that 'Seiobo' was the offspring of 'Kaga-wabisuke', which originated from 'Tarokaja', and the morphological characteristics of 'Misho' resemble 'Kocho-wabisuke' and 'Seiobo' [21,22]. On the other hand, Subgroup I-2 embraced all the C. japonica accessions as well as eight wabisuke camellias-'Eiraku', 'Fukurin-ikkyu', 'Ichiko-wabisuke', 'Ikkyu', 
'Kon-wabisuke', 'Kurume-ikkyu', 'Sado-wabisuke' and 'Sayo-wabisuke' - which are reported to have been established from C. japonica $[1,21,22]$. Flowers from 'Ichiko-wabisuke', 'Sado-wabisuke', 'Sayo-wabisuke' and 'Hamochi-wabisuke' have degenerated anthers, while 'Eiraku' (synonym: 'Kuro-wabisuke'), 'Fukurin-ikkyu', 'Ikkyu', 'Kon-wabisuke' and 'Kurume-ikkyu' bloom flowers with normal anthers. In this respect, the latter five cultivars should be excluded from wabisuke cultivars, although some of them are called "wabisuke". It was, therefore, estimated that the wabisuke cultivars in Subgroups I-1 and I-2 were established from 'Tarokaja' and C. japonica, respectively.

It has been reported that Chinese camellia species, such as C. pitardii var. pitardii $[1,4]$, C. saluenensis [6], C. reticulata [6] and C. sinensis [7] were involved in the establishment of the wabisuke camellias. Among them, Tanaka et al. [4] described that 'Tarokaja' is considered to be an $F_{1}$ hybrid of $C$. pitardii and $C$. japonica from a morphological and historical survey. In contrast, Kondo [23] reported that the wabisuke cultivars were established by an intraspecific mutation of $C$. japonica. Tanikawa et al. [8] reported that the maternal origin of 'Tarokaja' is the Chinese native species C. pitardii var. pitardii, and that wabisuke camellia cultivars are classified into two groups from the chloroplast DNA variation. They described that one group was thought to be derived from crosses between 'Tarokaja' and C. japonica, most of which had a 'Tarokaja'-type cpDNA, and the other was derived from C. japonica by mutation, with some exceptions.

It is known that chloroplast DNA variation provides the useful information for use in estimating the maternal ancestry, whereas AFLP analysis allows us to infer genetic relationships between the accessions involved in the establishment as maternals or paternals. The results of this experiment showed that the genetic distance between wabisuke cultivars and Chinese camellias and between wabisuke cultivars and C. sinensis was much further than the genetic distance between wabisuke cultivars and C. japonica. The NJ (neighbor-joining) method [18] divided the wabisuke cultivars into two subgroups. It was estimated that the wabisuke camellias in Subgroup I-2, including five C. japonica accessions, originated from C. japonica. Tanaka et al. [4] stated that 'Tarokaja' is considered to be an $\mathrm{F}_{1}$ hybrid between C. pitardii and C. japonica. If the 'Tarokaja (Uraku)' is an $\mathrm{F}_{1}$ hybrid between these species, the cultivar should be located in the middle position between $C$. pitardii var. pitardii and C. japonica on the NJ tree (Figure 2). It is, therefore, supposed that 'Tarokaja (Uraku)' is not an $\mathrm{F}_{1}$ hybrids between $C$. pitardii var. pitardii and C. japonica, and that those in Subgroup I-1 were established by the repeated hybridization of $C$. japonica to interspecific hybrids with the Chinese camellias, e.g., C. pitardii var. pitardii, or by the involvement of related species not investigated in this study.

Author Contributions: Conceptualization, J.-H.K. and Y.O.; methodology, I.K. and T.N.; software, I.K.; validation, J.-H.K. and M.H.; formal analysis, M.H.; investigation, I.K.; resources, H.O.; data curation, M.H. and Y.M.; supervision and project administration, H.O.; writing-original draft preparation, J.-H.K., I.K. and Y.O.; writing—review and editing, I.M., Y.M. and H.O. All authors have read and agreed to the published version of the manuscript.

Funding: This research received no external funding.

Data Availability Statement: Not applicable.

Conflicts of Interest: The authors declare no conflict of interest.

\section{References}

1. Kirino, S. Chaseki no Hana. Tsubaki to Wabisuke; Bunka-Shuppan-Kyoku: Tokyo, Japan, 1986; pp. 36-43. (In Japanese)

2. Savige, T.J. Uraku. In The International Camellia Register; The International Camellia Society: Wirlinga, NSW, Australia, 1993; Volume 2, p. 1904.

3. Miyajima, I.; Ozaki, Y.; Itateyama, M.; Ikematsu, R.; Okubo, H.; Goi, M. Genetic identity of old Camellia 'Uraku' trees existing in Japan. J. Jpn. Soc. Hortic. Sci. 2001, 70, 366-371. [CrossRef]

4. Tanaka, T.; Kirino, S.; Hakoda, N.; Fujieda, K.; Mizutani, T. Studies on the origin of Camellia wabiske. Proc. Sch. Agric. Kyushu Tokai Univ. 2001, 20, 1-7. 
5. Tamura, T.; Hagiya, K.; Hakoda, N. Tsubaki-zoku. In Engei-Shokubutsu-Daijiten; Aiga, T., Ed.; Shogakukan: Tokyo, Japan, 1989; pp. 267-275. (In Japanese)

6. Sakata, Y. Studies on the flower colours in the genus Camellia, with special reference to the phylogenies of the genus. Bull. Fac. Agr. Kagoshima Univ. 1988, 38, 9-62.

7. Kato, M.; Simura, T. Cytological studies on Camellia species II. The karyotype analysis in C. sinensis and C. wabiske. Jpn. J. Breed. 1971, 21, 265-268. [CrossRef]

8. Tanikawa, N.; Onozaki, T.; Nakayama, M.; Shibata, M. Maternal origin of 'Tarokaja' and other wabisuke camellia cultivars indicated by chloroplast DNA variation. J. Jpn. Soc. Hortic. Sci. 2010, 79, 77-83. [CrossRef]

9. Tanikawa, N.; Yoshida, K.; Kondo, T.; Mizuno, T.; Iwashina, T.; Nakayama, M. Urakunoside, a new tetraglycosyl kaempferol from petals of the wabisuke camellia cv. Tarokaja. Biosci. Biotechnol. Biochem. 2011, 75, 2046-2048. [CrossRef] [PubMed]

10. Perera, L.; Russell, J.R.; Provan, J.; McNicol, J.W.; Powell, W. Exaluating genetic relationships between indigenous coconut (Cocos nucifera L.) accessions from Sri Lanka by means of AFLP profiling. Theor. Appl. Genet. 1998, 96, 545-550. [CrossRef] [PubMed]

11. Kanzaki, S.; Yonemori, K.; Sato, A.; Yamada, M.; Sugiura, A. Analysis of the genetic relationships among pollination-constant and non-astringent (PCNA) cultivars of persimmon (Diospyros kaki Thunb.) from Japan and China using amplified fragment length polymorphism (AFLP). J. Jpn. Soc. Hortic. Sci. 2000, 69, 665-670. [CrossRef]

12. Ellis, R.P.; McNicol, J.W.; Baird, E.; Booth, A.; Lawrence, P.; Thomas, B.; Powell, W. The use of AFLPs to examine genetic relatedness in barley. Mol. Breed. 1997, 3, 359-369. [CrossRef]

13. Rabey, H.A.; Al-Malki, A.L.; Abulnaja, K.O.; Ebrahim, M.K.; Kumosani, T.; Khan, J.A. Phylogeny of ten species of the genus Hordeum L. as revealed by AFLP markers and seed storage protein electrophoresis. Mol. Biol. Rep. 2013, 41, 365-372. [CrossRef] [PubMed]

14. Yildizdogan, Z.; Ikten, C.; Mutlu, N.; Toker, C. Phylogeny of Lens taxa based on morphological and AFLP markers. J. Biotechnol. 2015, 208, S30. [CrossRef]

15. Drabkova, L.Z.; Pospiskova, M.; Businsky, R. Phylogeny and infrageneric delimitation in Spiraea (Rosaceae) inferred from AFLP markers and a comparison with morphology. Bot. J. Linn. Soc. 2017, 185, 525-541. [CrossRef]

16. Kobayashi, N.; Horikoshi, T.; Katsuyama, H.; Handa, T.; Tankayanagi, K. A simple and efficient DNA extraction method for plants, especially woody plants. Plant Tiss. Cult. Biotechnol. 1998, 4, 76-80.

17. Nei, M. Estimation of average heterozygosity and genetic distance from a small number of individuals. Genetics 1978, 89, 583-590. [CrossRef] [PubMed]

18. Saitou, N.; Nei, M. The neighbor-joining method: A new method for reconstructing phylogenetic trees. Mol. Biol. Evol. 1987, 4, 406-425. [PubMed]

19. Felesenstein, J. PHYLIP (Phylogeny Inference Package) Version 3.5c; Distributed by author; Department of Genetics, University of Washington: Seattle, WA, USA, 1993.

20. Japan Camellia Society (Ed.) Nihon-Tsubaki-Sazanka-Meikan; Seibundo-Shinkosha: Tokyo, Japan, 1998; p. 359. (In Japanese)

21. Yokoyama, Y.; Kirino, S. Nippon-no-Chinka; Tanko-Sha: Kyoto, Japan, 2005; p. 421. (In Japanese)

22. Kirino, S. Tsubaki; Gakken: Tokyo, Japan, 2005; p. 192. (In Japanese)

23. Kondo, K. Cytological studies in cultivated species of Camellia. Ph.D. Thesis, University of North Carolina, Chapel Hill, NC, USA, 1975 